\title{
To Compare and Demonstrate the Safety and Efficacy of Antithrombotic Agents and Fibrinolytics in the Management of Acute Coronary Syndrome Assessment, Evaluation and Management of Adverse Events
}

\author{
Bonaspur Srivani, Gandola Ashwini, Mangali Kalyani, Patheparupu Gopi Pavan Kumar, \\ Pharm D Interns, Nova College of Pharmaceutical Education and Research, Hyderabad India \\ Posani Bhavani \\ Pharm D Intern, Avanthi Institute of Pharmaceutical Sciences, Hyderabad, India
}

\begin{abstract}
Antithrombotic therapy and Fibrinolytics are central to the management of Acute Coronary Syndrome. These are high alert medications that are prone to adverse effects thus requiring strict monitoring. Effective usage of these medications results in reduction of recurrent ischaemic events including MI and stent thrombosis. Reducing the ischemic events and maintaining a balance between normal physiological coagulability and the bleeding is vital to avoid bleeding complications during the therapy. This therapy induced adverse effects increases mortality and morbidity rate. In our study we are mainly focussing on, comparing and demonstrating the effectiveness of enoxaparin over heparin and Tenecteplase over streptokinase and to assess, evaluate and management of adverse events by Narinjo assessment scale. Majority of adverse events were seen in subjects with social history of alcoholism, this shows alcoholism decreasing the threshold to adverse events. Causality assessment of adverse effects were $17.45 \%$ Possible and $91.6 \%$ were probable. The streptokinase was found superior than tenecteplase and enoxaparin was found superior than heparin in terms of adverse events and hospitalisation period. ACS is an drastic health disorder that increases the morbidity rate, mortality rate, economic burden and well being of the persons. Thus individualisation of drug regimen and strategies for early detection, monitoring and management of adverse events is mandatory.
\end{abstract}

Keywords:- Acute coronary syndrome, Fibrinolytics, Antithrombotics, Management.

\section{INTRODUCTION}

Acute Coronary Syndrome is one of the leading causes of significant mortality and morbidity in worldwide. In India poor patients were less likely to get evidence-based treatments, and had greater 30-day mortality than wealthy patients (8\% vs $6 \% \mathrm{p}<0.0001)$. This difference in mortality can be eliminated by adjustment in treatments [1].A study reported that the risk of major bleeding in Acute Coronary Syndrome patients have been increased by the use of multiple antithrombotic drugs and aggressive invasive strategies, This major bleeding in case of emergency conditions may cause hypovolemia condition or hypotension and may cause fatal situations, These increases Hospitalisation, disrupts the quality of life and the patients well being thus cautious and selective use of these antithrombotic agents and fibrinolytics may decrease adverse effects. A study showed that When Compared to streptokinase in the treatment of STEMI Tenecteplase was the most safest and efficacious fibrinolytic agent,Co morbidities of patients did not affect the resolution of ST segment in both fibrinolytic agents[2].Our Study is mainly focussed on To compare and demonstrate effectiveness of Enoxaparin over heparin and Tenecteplase over Streptokinase and to assess, evaluate and management of adverse drug reactions incurred by antithrombotics and fibrinolytics. This study provides information in the management of therapy induced bleedings in ACS and comparison of drugs in terms of safety and effectiveness. Antithrombotic agents are associated with adverse effects even though they play a crucial role in the management of acute coronary syndrome.

Acute Coronary Syndrome (ACS) is defined as group of syndromes which resulting from imbalance between myocardial oxygen demand and supply to heart myocardium by coronary arteries [3].

Based on Electrocardiographic changes (ECG) ACS can be classified as

- ST segment Elevation Myocardial infarction

- Non ST segment elevation includes Unstable angina and Non ST Segment Elevation Myocardial Infarction [3].

Symptoms: Chest pain or chest discomfort, Pain radiating to neck, shoulders,arms back or jaw, Pain in abdomen,shortness of breath,Indigestion,Nausea and vomiting,fainting, weakness and sweating[3].

MI Complications: Cardiogenic shock, Heart failure, arrythmias, dysfunction, Pericardities, Stroke secondary to left Ventricular (LV) thrombus embolization, Venous thromboembolism and LV free wall rupture [3] 


\section{Pharmacological Therapy of Stemi:}

Therapy of STEMI includes oxygen administration, antiplatelet therapy (Aspirin, Thienopyridines (Clopidogrel, Prasugrel), Glycoprotein IIB/IIIA inhibitors (Abciximab, Tirofiban and Eptifibatide), Nitrates, Anticoagulation therapy,Calcium channel blockers,HMG COA Reductase Inhibitors,Beta blockers, Angiotensin Converting enzyme inhibitors, Angiotensin II receptor blockers,Morphine and aldosterone antagonists(Spironolactone) and fibrinolytic therapy(Streptokinase,urokinase,tenecteplase,alteplase and reteplase)and PCI(Percutaneous Coronary Intervention) [3]
Pharmacological Therapy of NON-STEMI: Therapy includes Anticoagulants, Antiplatelets, Calcium channel blockers, Beta blockers, ACE Inhibitors, Angiotensin II receptor blockers, Nitrates and Statins [3].

\section{- Abbreviations:}

Pharmacological Therapy Of Unstable Angina: Therapy includes Anticoagulants(Heparin,Bivalirudin), Antiplatelets(Aspirin, Clopidogrel, prasugrel, ticagrelor, Abciximab, Eptifibatide and tirofiban) Statins, Nitrates, Calcium Channel blockers, Angiotensin converting enzyme Inhibitors, Ranolazine, Trimetazidine and Nicorandil [3].

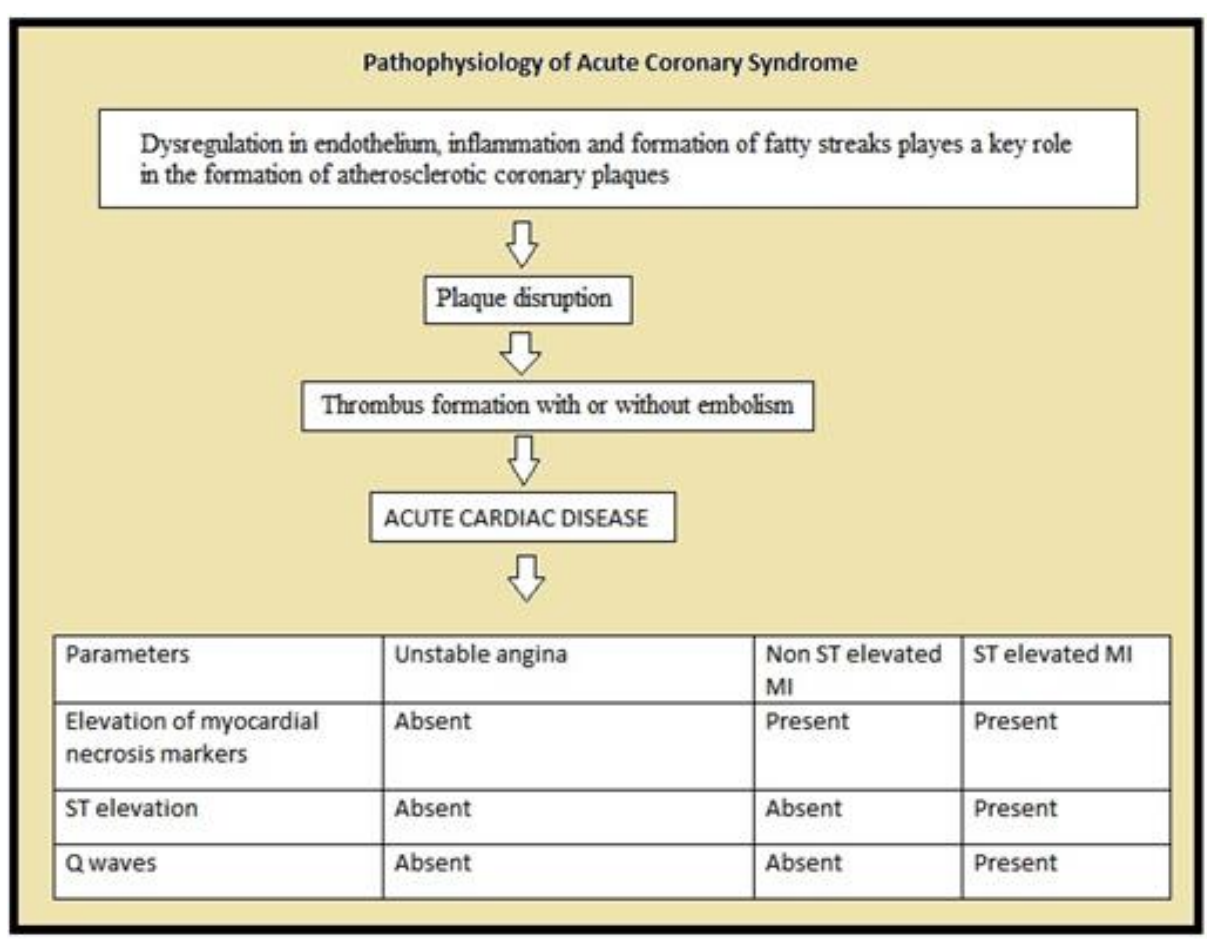

Fig 1:- Pathophysiology of Acute Coronary Syndrome

\section{Fibrinolytics:}

Fibrinolytic therapy should be administered to STEMI patients with symptom onset of chest discomfort within the prior 12 hours to those who have at least $1 \mathrm{~mm}$ of ST Elevation in two or more adjacent ECG leads and are unable to undergo primary PCI within 120 minutes of medical contact or due to non availability of PCI (Percutaneous Coronary Intervention) in nearby hospital. In symptom onset patients with ongoing ischemia limit the use of fibrinolytics between 12 and 24 hours [4]

\section{Streptokinase:}

- It is a non-fibrin specific that is it inactivates both the circulating and fibrin bound plasminogen fibrinolytic agent.

- Route of administration: Intravenous infusion and intracoronary infusion.

- Dosage of Streptokinase in MI: 1,500,00 IU administered intravenously within a $60 \mathrm{~min}$ period.

- Intracoronary infusion: 20,000IU administered as an IV bolus and it is followed by infusion of 2,000 IU/min for $60 \mathrm{~min}$ resulting in total dose of $1,40,000 \mathrm{IU}$ [5].

\section{Tenecteplase:}

- This is genetically engineered substitution mutant of tPA with higher fibrin specificity.

- Total Recommended dose should not exceed 50mg,

- Tenecteplase dosed 30-50mg Intravenous bolus over 5 sec once based on individual weights. If patient weight is < 60 years dose should be $30 \mathrm{mg}, 35 \mathrm{mg}$ if weight is $60-69,40 \mathrm{mg}$ if weight is $70-79,45 \mathrm{mg}$ if weight is 80 $89 \mathrm{~kg}$, and $50 \mathrm{mg}$ is recommended if the weight is greater than $90 \mathrm{~kg}[6]$.

\section{$>$ Anticoagulants:}

Heparin is anon-uniform mixture of mucopolysaccharides with the molecular weight of 10,000 to 20,000

Dose of Heparin for Primary PCI:

- A initial IV bolus of 70-100 units $/ \mathrm{kg}$ is recommended without Glycoprotein IIb/IIIaInhibitors.

- A initial IV bolus of 50-70 units $/ \mathrm{kg}$ is recommended with Glycoprotein IIb/IIIa Inhibitors [7]. 
Dose in STEMI: In patients with fibrinolytics a recommended dose of Heparin include a Intravenous bolus of 60 units $/ \mathrm{kg}$ (maximum dose:4000 units) and it is followed by 12 units/kg/HR (maximum 1000 units/hour) as continuous infusion.Dose of Heparin to be adjusted to maintain target aPTT(Activated partial Thromboplastin time)of 50-70 sec [7].

Dose in Unstable angina/NSTEMI: Recommended initial IV Bolus of 60-70 units $/ \mathrm{kg}$ ( maximum-5000 units)Then followed by IV infusion of $12-15$ units $/ \mathrm{kg} / \mathrm{hr}$ (maximum:1000 units/hour ,Dose of Heparin to be adjusted to maintain target APTT of 50-70 sec[7].

Enoxaparin: Fractionated heparin with the molecular weight of 3000-7000

Prophylaxis of ischemic complications in unstable angina and NSTEMI:

A recommended dose of $1 \mathrm{mg} / \mathrm{kg}$ subcutaneously every 12 hours in concomitance with oral aspirin therapy (100-325 once a day).Duration of therapy will be 2 days and until clinical stabilization and usual duration of therapy is likely to be 2 to 8 days.

Dose in Acute STEMI who are receiving fibrinolytics:30 mg/kg IV bolus followed by $1 \mathrm{mg} / \mathrm{kg}$ subcutaneously for every 12 hours in people younger than 75 years and those who are older than 75 years $0.75 \mathrm{mg} / \mathrm{kg}$ SC for every 12 hours, Duration of therapy is likely to be 8 days or throughout Hospitalization[8].

\section{Management of Adverse Effects Associated With Antithrombotics And Fibrinolytics:}

Bleeding: Strategies to reduce the risk of bleeding should include

- Avoid placing nasotracheal tube and naso gastric tubes

- Monitor the patient for every $15 \mathrm{mins}$ during the treatment for internal haemorrhaging

- Selection of patients carefully for invasive procedures in patients with lower ischemic risk and high bleed risk in patients with non-urgent CABG surgery who has received P2Y12 Inhibitors for them delaying of procedures to be considered.

- Some procedural techniques can decrease bleeding risk such as Femoral approaches vs. Radial artery approaches to PCI,Radial artery approach to PCI access site reduces the bleeding incidence and is the most commonly used approaches to PCI.

- For active bleeding venipuncture sites apply direct pressure for at least 5 minutes [10]

- Apply manual pressure to the bleeding site

- Monitor blood count, prothrombin time, APTT, fibrinogen concentration..

- De escalation of the therapy
In the case of excessive bleeding due to thrombolytic therapy, antidote aminocaproic acid is given $5 \mathrm{mg}$ PO or slow IV follow by a dose of $1.25 \mathrm{~g}$ every $\mathrm{hr}$ up to maximum dose of $30 \mathrm{~g}$ total in a $24 \mathrm{hr}$ period.

Hypotension: Administration of crystalloid volume replacementsand intravenous fluids is preferred.

Gastrointestinal Bleeding:_People who are high risk of GI Bleeding, proton pump inhibitors are administered orally to suppress stomach acid prior to the anticoagulant or fibrinolytic therapy and de-escalation of therapy is preferred.

Abnormal liver function values: monitoring of Liver function tests, de-escalation of therapy.

Hypersensitivity reactions: Symptomatic treatment, corticosteroids and drug replacement

Thrombocytopenia:

Heparin-induced thrombocytopenia can be treated by discontinuing heparin and starting a non-heparin anticoagulant.

Argatroban or bivalirudin owing to their shorter duration of effect can be used in critically ill patients and increased bleeding risk, or increased need before urgent procedure.Fondaparinux or direct oral anticoagulants (DAOC) are recommended for clinically stable patients because of their ease of administration and devoid of lab monitoring and feasible for outpatient use.

Argatroban, bivalirudin, danaparoid, or fondaparinux are recommended for Life-threatening or limb-threatening thrombosis

In the case of over activity of heparin, protamine sulphate is used, $1 \mathrm{mg}$ per 100 units of heparin IV is administered in adults.

$>$ Abbreviations:

ACS-Acute Coronary Syndrome

DM- Diabetes Mellitus

HTN- Hypertension

LFT-Liver Function Test

Objectives:

- To identify, evaluate and manageadverse effects resulted from ACS therapy

- To demonstrate the efficacy of tenecteplase over streptokinase.

- To demonstrate the efficacy of enoxaparin over heparin.

$>$ Study Site:

This is a prospective observational study carried out in Gandhi hospital, Hyderabad with study duration of 6 months (October 2018 - March 2019).

Study materials:

Naranjo ADR assessment scale. 


\begin{tabular}{|c|c|c|c|c|}
\hline Question & Yes & No & Do Not Know & Score \\
\hline 1. Are there previous conclusive reports on this reaction? & +1 & 0 & 0 & \\
\hline $\begin{array}{l}\text { 2. Did the adverse event appear after the suspected drug } \\
\text { was administered? }\end{array}$ & +2 & -1 & 0 & \\
\hline $\begin{array}{l}\text { 3. Did the adverse event improve when the drug was dis- } \\
\text { continued or a specific antagonist was administered? }\end{array}$ & +1 & 0 & 0 & \\
\hline $\begin{array}{l}\text { 4. Did the adverse event reappear when the drug was } \\
\text { readministered? }\end{array}$ & +2 & -1 & 0 & \\
\hline $\begin{array}{l}\text { 5. Are there alternative causes that could on their own } \\
\text { have caused the reaction? }\end{array}$ & -1 & +2 & 0 & \\
\hline 6. Did the reaction reappear when a placebo was given? ${ }^{*}$ & -1 & +1 & 0 & \\
\hline $\begin{array}{l}\text { 7. Was the drug detected in blood or other fluids in con- } \\
\text { centrations known to be toxic? }\end{array}$ & +1 & 0 & 0 & \\
\hline $\begin{array}{l}\text { 8. Was the reaction more severe when the dose was in- } \\
\text { creased or less severe when the dose was decreased? }\end{array}$ & +1 & 0 & 0 & \\
\hline $\begin{array}{l}\text { 9. Did the patient have a similar reaction to the same or } \\
\text { similar drugs in any previous exposure? }\end{array}$ & +1 & 0 & 0 & \\
\hline $\begin{array}{l}\text { 10. Was the adverse event confirmed by any objective } \\
\text { evidence? }\end{array}$ & +1 & 0 & 0 & \\
\hline & & & Total Score: & \\
\hline
\end{tabular}

"Question 6 refers to a typical clinical trials situation and is included here for completeness.

\begin{tabular}{|c|l|}
\hline $\begin{array}{c}\text { Total } \\
\text { Score }\end{array}$ & Interpretation of Scores \\
\hline$\geq 9$ & $\begin{array}{l}\text { Definite. The reaction (1) followed a reasonable temporal sequence after drug exposure had been es- } \\
\text { tablished in body fluids or tissues, (2) followed a recognized response to the suspected drug, (3) was } \\
\text { confirmed by improvement on withdrawing the drug and (4) reappeared on reexposure. }\end{array}$ \\
\hline $5-8$ & $\begin{array}{l}\text { Probable. The reaction (1) followed a reasonable temporal sequence after a drug exposure, (2) followed a } \\
\text { recognized response to the suspected drug, (3) was confirmed by withdrawal but not by exposure to the } \\
\text { drug, and (4) could not be reasonably explained by the known characteristics of the patient's clinical state. }\end{array}$ \\
\hline $1-4$ & $\begin{array}{l}\text { Possible. The reaction (1) followed a temporal sequence after a drug exposure, (2) possibly followed a recog. } \\
\text { nized pattern to the suspected drug, and (3) could be explained by characteristics of the patient's disease. }\end{array}$ \\
\hline$\leq 0$ & Doubtful. The reaction was likely related to factors other than a drug. \\
\hline
\end{tabular}

The Naranjo scale is a tool to help clarify how to evaluate a potential causal association. It is not intended to solve all the complex problems of identification and classification of ADRs.

Fig 2

- Case report form

\section{Source of Data:}

- Patient's medication profile.

- Physicians prescribing records.

- Nursing charts.

\section{STUDY CRITERIA}

> Inclusion Criteria:

- Age criteria- 30 years above.

- Subjects with confirmed diagnosis of acute coronary syndrome patients, Coronary artery disease patient and heart failure patients.
Exclusion Criteria:

- Pregnant and lactating women.

- Patients below 30 years.

- Surgery patients.

\section{RESEARCH METHODOLOGY}

Protocol, case report forms and ICFs were prepared and were submitted to institutional review board for approval and after getting approval, the study was done as follows

$>$ Subject medical data collection

$>$ Application of Naranjo by ADR assessment scale

$>$ Data recording

$>$ Data analysis

$>$ Reporting 
ISSN No:-2456-2165

Statistical analysis: Analysis was done by using SPSS Software $24^{\text {th }}$ version and Microsoft excel 2007.

\section{RESULTS AND DISCUSSION}

During the study Period around 927 patients visited the hospital. From that 150 subjects were diagnosed withcardiovascular disease so; the prevalence of cardiovascular disease was found tobe 161.8 per 1000 population

Prevalence: Number of subjects with ACS $\quad \times 1000$ Total No Of Population with ACS

In this study a total of 150 patients were selected by the inclusion and exclusion criteria. Out of the 150 subjects selected $82(60.2 \%)$ subjects were male and the subjects 68 $(39.8 \%)$ patients were female. The patients were divided in different agegroups

\begin{tabular}{|c|c|}
\hline Age & Percentage (\%) \\
\hline $30-40$ & $1.6 \%$ \\
\hline $40-50$ & $12.4 \%$ \\
\hline $50-60$ & $30 \%$ \\
\hline $60-70$ & $29 \%$ \\
\hline $70-80$ & $18 \%$ \\
\hline $80-90$ & $6 \%$ \\
\hline $90-100$ & $3 \%$ \\
\hline
\end{tabular}

Table 1:- Categorisation based on Age

Discussion: The ACS found to be more in the age groups, 50-60 and 60-70 years.

\begin{tabular}{|c|c|c|}
\hline Adverse Events & $\begin{array}{c}\text { Subjects On } \\
\text { Heparin } \\
\text { Medication } \\
\text { With Adverse } \\
\text { Effects }\end{array}$ & $\begin{array}{c}\text { Subjects On } \\
\text { Enoxaparin } \\
\text { Medication With } \\
\text { Adverse Effects }\end{array}$ \\
\hline Thrombocytopenia & 39 & 8 \\
\hline $\begin{array}{c}\text { Elevated AST } \\
\text { Levels And LFS }\end{array}$ & 12 & 5 \\
\hline $\begin{array}{c}\text { Hypersensitivity } \\
\text { Reactions }\end{array}$ & 8 & 1 \\
\hline Haematuria & 29 & 3 \\
\hline Blood Vomiting & 11 & 8 \\
\hline Gum Bleeding & 23 & 3 \\
\hline
\end{tabular}

Table 2:- To compare the effectiveness of Enoxaparin over Heparin

Discussion : frequency of adverse effects in subjects with enoxaparin is significantly less on comparison with frequency of the subjects with heparin with $\mathrm{p}$ - value of 0.01 (t-test)

\begin{tabular}{|c|c|}
\hline Comorbidities & Frequency \\
\hline DM-II, HTN & $43(28.6 \%)$ \\
\hline HTN & $75(50 \%)$ \\
\hline DM & $5(3.3 \%)$ \\
\hline Acidity & $2(1.3 \%)$ \\
\hline Hypothyroidism & $1(0.6 \%)$ \\
\hline DVT & $10(6.6 \%)$ \\
\hline
\end{tabular}

Table 3:- Co morbidities and ACS

\begin{tabular}{|c|c|c|}
\hline Adverse Events & $\begin{array}{c}\text { Subjects On Streptokinase } \\
\text { Medication With Adverse } \\
\text { Effects }\end{array}$ & $\begin{array}{c}\text { Subjects On TenecteplaseMedication With Adverse } \\
\text { Effects }\end{array}$ \\
\hline Irregular Heart Rate & 3 & 2 \\
\hline Melena/ Blood In Stool & 2 & 0 \\
\hline Haematuria & 4 & 2 \\
\hline Hypotension & 7 & 1 \\
\hline Liver Enzymes Elevation & 5 & 1 \\
\hline
\end{tabular}

Table 4:- To compare the effectiveness of Tenecteplase over Streptokinase

Discussion: Adverse effects of subjects on streptokinase medications are significantly higher than the subjects on tenecteplase.

\begin{tabular}{|c|c|}
\hline Probability & Percentage \\
\hline Possible & $17.4 \%$ \\
\hline Probable & $91.6 \%$ \\
\hline
\end{tabular}

Table 5:- Application of Naranjo Scale
The subjects with the history of hypertension the risk of ACS and second comes the DM and HTN together predisposing to the ACS, thus appropriate management of the comorbidities is needed in order to suppress the sprouting of other diseases.

Discussion: Among 150subjects, 32 subjects were alcoholic \&smoker (32), 15 subjects were alcoholic, 16 subjects were alcoholic \& tobacco chewer, 2subjects were ex-alcoholic, 1 subject was ex-smoker \& alcoholic. Majority of adverse events were seen in subjects with social history of alcoholism, this shows alcoholism decreasing the 
threshold to adverse events.Casuality assessment of adverse drug reactions are $17.45 \%$ Possible and $91.6 \%$ were probable. The hospitalisation period was comparatively more for the subjects with heparin and streptokinase. The streptokinase was found superior than tenecteplase and enoxaparin was found superior than heparin in terms of adverse events, hospitalisation period.

\section{CONCLUSION}

ACS is a drastic health disorder that increases the morbidity, mortality and well being of the subjects and in addition the ACS therapy is associated with adverse events that increase the hospitalisation period, economic burden and well being of the persons. Thus individualisation of drug regimen and strategies for detection, monitoring and management of adverse events is needed.

\section{ACKNOWLEDGEMENT}

I would like to thank health care professionals in the Gandhi hospital for supporting me in conducting the study.

\section{REFERENCES}

[1]. https://cadiresearch.org/topic/asian-indian-heartdisease/cadi-india/acute-coronary-syndrome-india

[2]. To demonstrate the effectiveness of streptokinase... Google Scholar @MIUI https://scholar.google.com/scholar?start=10\&q=To+d emonstrate+the+effectiveness+of + streptokinase $+v s+t$ enecteplase\&hl=en\&as_sdt $=0,5 \# d=g s \_q a b s \& u=\% 23 p$ \%3Dhx_OihvzwrkJ

[3]. Pharmacotherapy hand book ninth edition, Barbara G. Wells PharmD,Joseph T. DiPiroPharmD FCCP, Terry L. Schwinghammer PharmD, Cecily V. DiPiro, PharmD.

[4]. https://emedicine.medscape.com/article/159383treatment\#d8

[5]. https://www.drugs.com/dosage/streptokinase.html

[6]. https://www.tnkase.com/dosing-andadministration/dosing-guidelines.html

[7]. https://reference.medscape.com/drug/calciparinemonoparin-heparin-342169

[8]. https://www.drugs.com/dosage/enoxaparin.html.

[9]. https://emedicine.medscape.com/article/1357846medication\#1

[10]. https://www.scribd.com/document/208383436/Studen tManual-Thrombolytics-2 